\title{
Penanaman Motifasi Berprestasi pada Mahasiswa Baru Program Studi Fisika, FKIP, Universitas Mataram
}

\author{
Muhammad Zuhdi ${ }^{1 *}$, Syahrial Ayub ${ }^{1}$, Muhammad Taufik $^{1}$, Bakti Sukrisna ${ }^{2}$, Syamsuddin $^{2}$ \\ ${ }^{I}$ Program Studi Pendidikan Fisika, FKIP, Universitas Mataram, Lombok, Indonesia \\ ${ }^{2}$ Program Studi Fisika, FMIPA, Universitas Mataram, Lombok, Indonesia
}

DOI: https://doi.org/10.29303/.jpmsi.v2i1.35

Citation: Zuhdi, M., Ayub, S., Taufik, M., Sukrisna, B., Syamsuddin. 2020. Penanaman Motifasi Berprestasi pada Mahasiswa Baru Program Studi Fisika, FKIP, Universitas Mataram. Jurnal Pengabdian Masyarakat Sains Indonesia (JPMSI). 2(1): 89-91.

Article history

Received: Mei $14^{\text {th }} 2020$

Revised: Mei $18^{\text {th }} 2020$

Accepted: Mei $28^{\text {th }} 2020$

*Corresponding Author: Muhammad Zuhdi, Program Studi Pendidikan Fisika, FKIP, Universitas Mataram, Lombok, Indonesia.

Email: mzuhdi@unram.ac.id

\begin{abstract}
Abstrak: Masalah yang dihadapi oleh mahasiswa baru pada program studi Pendidikan Fisika, Jurusan PMIPA, FKIP, Universitas Mataram adalah masalah akademik maupun non akademik. Untuk mengatasi masalah-masalah yang dihadapi mahasiswa baru tersebut, Himpunan Mahasiswa fisika menyelenggarakan workshop dengan tema meningkatkan motivasi untuk berprestasi. Pemateri pada workshop ini adalah dosen fisika dan kakak tingkat yang merupakan mahasiswa-mahasiswa berprestasi, baik di bidang akademik maupun non akademik. Workshop semacam ini sangat dirasakan manfaatnya oleh mahasiswa baru, sebagai upaya untuk memotivasi semangat belajar dan berprestasi serta menyikapi permasalahan yang dihadapi dengan proporsional.
\end{abstract}

Kata Kunci: masalah, mahasiswa baru, motivasi berprestasi

Abstract: The problem faced by new students majoring in physics teaching study programs at the Department of Mathematics and Natural Sciences in Faculty of Education, Mataram University is academic and non-academic problems. To overcome the problems faced by the new students, the Physics Student Association held a workshop with the theme of increasing motivation for achievement. Presenters in this workshop are physics lecturers and senior level students who are outstanding students in both academic and non-academic fields. This kind of workshop are very useful for new students in an effort to motivate learning and achievement and address problems posed proportionally.

Keywords: problems, new students, achievement motivation

\section{Pendahuluan}

Ketika masuk dunia perguruan tinggi mahasiswa baru dapat mengalami berbagai permasalahan. Permasalahan tersebut dapat berupa permasalahan psikis, terhadap lingkungan kampus yang baru, terhadap sesama mahasiswa, maupun terhadap dosen dan pengajar di lingkungan perguruan tinggi.

Beberapa mahasiswa diantaranya mengalami permasalahan lainnya yaitu merasa tidak cocok dengan program studi yang ia pilih. Kelompok mahasiswa tersebut merasa bahwa jurusan yang ia pilih tidak seperti yang ia bayangkan sebelumnya. Permasalahan ini menjadikan mahasiswa kurang memiliki semangat dan antusiasme dalam mengikuti kegiatan akademik, baik kuliah, tugas maupun praktikum. Beberapa orang mahasiswa jurusan fisika mengalami hal ini. Mereka merasa ketika belajar di SMA, fisika adalah pelajaran yang menyenangkan dan mudah mereka pahami. Akan tetapi ketika mengikuti perkuliahan-perkuliahan di perguruan tinggi, masalah-masalah yang timbul dan mereka hadapi menjadi sangat berbeda.

Mahasiswa tidak terbiasa dengan belajar mandiri sehingga masih mengharapkan pemaparan materi secara direct instruction seperti yang dilakukan gurunya ketika masih di sekolah menengah atas atau sekolah kejuruan. Untuk 
Zuhdi et al, Jurnal Pengabdian Masyarakat Sains Indonesia 2020, 2 (1):89-91 DOI : https://doi.org/10.29303/ipmsi.v2i1.35

menangani masalah-masalah yang dihadapi oleh mahasiswa baru, Himpunan Mahasiswa fisika, FKIP, Universitas Mataram mengadakan kegiatan untuk memacu semangat juang adik-adik mahasiswa baru dalam menggapai prestasi.

Acara yang diadakan oleh mahasiswa tersebut berjudul : Melalui Kompetensi, Gali Potensi, Ukir Prestasi, Bersama Himafis. Melalui acara tersebut diharapkan Mahasiswa dapat terpacu semangatnya untuk belajar lebih giat lagi dan mengesampingkan permasalahan yang mereka anggap berat menjadi masalah biasa dengan menyikapinya secara proporsional.

Guru seharusnya merupakan sosok Tangguh yang mampu menghadapi setiap masalah yang ada sebagai teladan bagi para siswanya. Guru juga harus siap menghadapi segala tantangan jika ia bertugas di berbagai daerah terpencil (Febriana dkk., 2018).

Masalah lain yang dihadapi mahasiswa baru adalah kurangnya bekal pengetahuan awal yang memadai untuk mengikuti materi kuliah yang diajarkan oleh para dosen. Mahasiswa di FKIP tidak mendapatkan program matrikulasi bagi materi yang kurang difahami. Padahal program matrikulasi terbukti efektif dalam meningkatkan bekal kemampuan awal bagi mahasiswa baru.

Susiaty, 2016, menyatakan bahwa nilai matrikulasi mahasiswa dengan kecerdasan interpersonal tinggi, kecerdasan interpersonal sedang maupun kecerdasan interpersonal rendah tergolong gagal, namum memberi kontribusi positif sebagai bekal awal. Pogram matrikulasi juga mampu meningkatkan hasil belajar materi kimia mahasiswa secara signifikan dengan peningkatan 76\% (Syahputra, Daulay, \& Ridwanto, 2016). Hal ini juga diperkuat oleh penelitian yang dilakukan Rosliana, Permanasari, \& Sudargo, pada tahun 2014, yang menyatakan bahwa kegiatan matrikulasi terbukti penting untuk peserta didik dengan berbagai latar belakang tingkat kemampuan yang berbeda-beda. Program matrikulasi juga terbukti dapat digunakan untuk meningkatkan nilai TOEFL mahasiswa (Herwandar, Safryono, \& Haryono, 2012).

\section{Metode}

Untuk mengatasi masalah yang dihadapi oleh mahasiswa tersebut, Himpunan Mahasiswa Fisika dibantu oleh pihak program studi jurusan dan
e-ISSN : $2715-2537$

p-ISSN : 2715-2545

fakultas menyelenggarakan acara dengan tema peningkatan motovasi berprestasi.

Format acara ini memiliki tujuan untuk menumbuhkan semangat dan rasa percaya diri yang tinggi pada mahasiswa baru untuk meraih prestasi dan menyelesaikan studi hingga mendapat gelar sarjana.

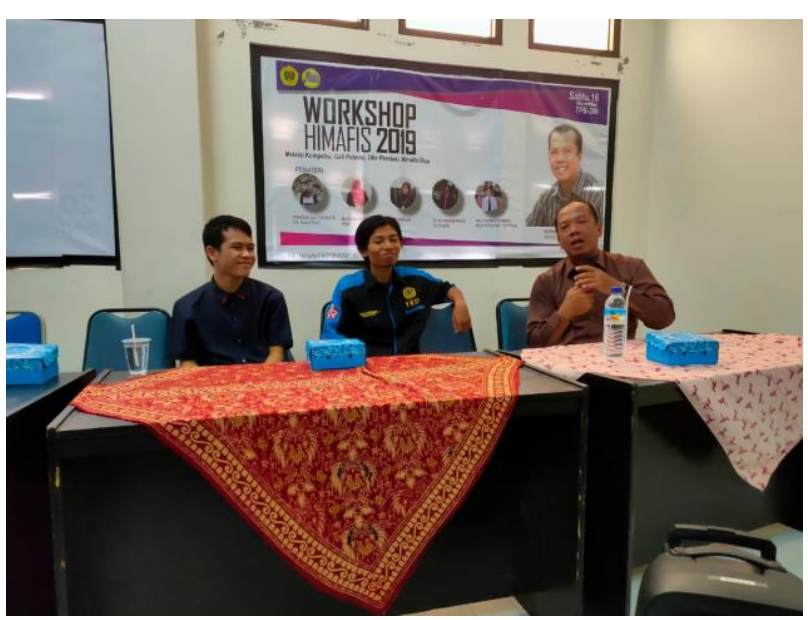

Gambar 1 Penyampaian materi workshop oleh dosen fisika

Kegiatan ini juga dimaksudkan untuk mencegah mahasiswa baru agar tidak segera memutuskan berpindah program studi hanya karena menghadapi beberapa masalah yang dihadapi.

Pola pendidikan dan pengajaran pada program studi fisika jurusan pmipa FKIP Universitas Mataram yang dilakukan oleh dosen memang cenderung berbeda dengan yang disampaikan oleh guru mereka saat SMA. Hal ini disebabkan karena beberapa dosen di program studi fisika memiliki keahlian pada bidang pengajaran, sehingga beberapa metode pembelajaran terkini diterapkan pada pengajaran yang diuji-cobakan pada mahasiswanya.

Salah satu metode pembelajaran yang diterapkan adalah perubahan konseptual melalui konflik kognitif. Ternyata pembelajaran dengan metode ini membuat bingung beberapa mahasiswa yang harus berpikir keras untuk merubah konsep awal yang mereka miliki yang ternyata salah dan tidak sesuai dengan konsep ilmiah yang sesungguhnya.

Melalui konflik kognitif semestinya mahasiswa menjadi paham terhadap konsep yang sebenarnya akan tetapi sebagian dari mahasiswa justru mengalami ketidaknyamanan dan merasa 
Zuhdi et al, Jurnal Pengabdian Masyarakat Sains Indonesia 2020, 2 (1):89-91 DOI : https://doi.org/10.29303/ipmsi.v2i1.35

frustrasi dengan pembelajaran yang berdasar pada konflik kognitif ini.

Pada pelatihan ini dosen memberi arahan kepada mahasiswa agar tidak mudah putus asa dan memberi semangat kepada mereka dengan cara memberikan contoh bahwa semua orang hidup pasti memiliki masalah, akan tetapi yang menjadi kita maju bukankah berhenti pada permasalahan itu sendiri, akan tetapi cara dan sikap kita yang tepat dalam menyelesaikan masalah tersebut.

Narasumber lain yang yang memberikan pelatihan pada acara ini adalah mahasiswamahasiswa dengan prestasi-prestasi yang membanggakan diantaranya IPK tertinggi juara nasional karya ilmiah dan lain sebagainya.

Pelatihan semacam ini diharapkan dapat menyelesaikan permasalahan-permasalahan yang dihadapi oleh mahasiswa baru.

Narasumber dosen pada acara ini diharapkan mampu memberi semangat pada mahasiswa untuk tidak mudah menyerah Narasumber mahasiswa senior berprestasi pada pelatihan ini diharapkan mampu memberikan tips dan sharing pengalaman dalam menghadapi masalah serta menyiasatinya sehingga tetap dapat berprestasi.

\section{Hasil dan Pembahasan}

Kegiatan workshop ini diikuti oleh seluruh mahasiswa baru pada Program Studi Fisika, Jurusan PMIPA, FKIP, universitas Mataram. Mahasiswa baru pada jurusan ini terbagi menjadi 3 kelas dengan persentase jenis kelamin 1/4 laki-laki dan $3 / 4$ perempuan.

Semua mahasiswa yang mengikuti acara ini merasa sangat antusias dengan materi yang disampaikan oleh dosen maupun kakak angkatan mereka yang berprestasi. Mahasiswa menjadi di lebih percaya diri dalam menyikapi permasalahan yang dihadapi selama di perguruan tinggi dan bersikap secara proporsional. Mahasiswa juga merasa terpacu untuk berprestasi sebagaimana yang dialami oleh kakak tingkat mereka yang berprestasi.

\section{Kesimpulan}

Kegiatan semacam ini sangat bermanfaat bagi mahasiswa baru dalam menambah wawasan tentang cara menghadapi masalah sebagai mahasiswa baru dan meningkatkan motivasi untuk berprestasi. Acara semacam ini dapat diprogramkan secara periodik pada tahun-tahun berikutnya.
e-ISSN : $2715-2537$

p-ISSN : 2715-2545

\section{Ucapan Terimakasih}

Ucapan terimakasih kami sampaikan kepada semua pihak yang telah membantu kelancaran penyelenggaraan acara workshop Himafis tahun 2019 ini.

\section{Daftar Pustaka}

Febriana, M., Nurkamto, J., Rochsantiningsih, D.,\& Muhtia, A. (2018). Teaching in Rural Indonesian Schools : Teachers, Challenges. International Journal of Multicultural and Multireligious Understanding, 5(5), 11-20. Retrieved from https://ijmmu.com/index. php/ijmmu/article/view/305/232

Herwandar, R., Safryono, D. A., \& Haryono, P. Y. (2012). Evaluasi Program Matrikulasi "TOEFL" Mahasiswa Universitas Al Azhar Indonesia 2010/2011. Jurnal Al-Azhar Indonesia Seri Humaniora, 1(3), 179-188. Jana, P. (2017). Pembinaan Olimpiade Matematika Kelas VA CI SD Negeri Ungaran I Yogyakarta. J-Dinamika, 2(2), 125-128.

Rosliana, N., Permanasari, A., \& Sudargo, F. (2014). Gambaran Hasil Belajar Matrikulasi Kimia Kesehatan di Program Studi S1 Kesehatan Masyarakat STIKES Dharma Husada Bandung. Jurnal Pendidikan Matematika Dan Sains, 2(2), 187-194.

Susiaty, U. D. (2016). Eksperimentasi Matrikulasi Ditinjau dari Kecerdasan Interpersonal Mahasiswa Semester I Program Studi Pendidikan Matematika IKIP PGRI Pontianak. Jurnal Pendidikan Informatika Dan Sains, 5(1), 130-141.

Syahputra, R. A., Daulay, A. S., \& Ridwanto. (2016). Upaya Peningkatan Hasil Belajar Kimia Pada Mahasiswa Baru Prodi Farmasi 2015/2016 UMN Al-Washliyah. Jurnal Penelitian Pendidikan MIPA, 1(1), 27-33. 